\title{
Response to TRH in suspected hypopituitarism
}

\author{
R D G MILNER AND S M HERBER
}

\author{
Department of Paediatrics, University of Sheffield
}

SUMMARY A retrospective analysis was made of 405 thyrotrophin-releasing hormone (TRH) stimulation tests on children who were successful applicants for growth hormone (GH) therapy in the UK between 1977 and 1981 inclusive. Thyroid-stimulating hormone (TSH) responses to TRH were divided into normal and those indicating pituitary or hypothalamic disease on the basis of criteria which eliminated variation in TSH assay between laboratories. Among children known to be hypothyroid $93 \%$ had abnormal TRH stimulation tests, but $35 \%$ of those children who were clinically euthyroid and who had normal serum thyroxin levels also had abnormal TSH responses to TRH. Abnormal TRH tests in the latter group were most common in euthyroid children who had GH deficiency with clearly defined aetiology and least common in those with idiopathic GH deficiency. Further work is required to clarify the interpretation of an abnormal TRH stimulation test in this group of children, but until this is done, such patients should be kept under regular review with respect to thyroid function.

Protirelin, or thyrotrophin-releasing hormone(TRH), is a tripeptide amine synthesised in the hypothalamus and a powerful stimulus to both thyroid-stimulating hormone (TSH) and prolactin secretion in adults and children. ${ }^{1-3}$ Synthetic TRH is used to test the competence of the pituitary to secrete TSH, and this test is often performed on children in the UK as part of the endocrine evaluation before the patient is considered as a candidate for growth hormone (GH) therapy. Despite wide use of the test, information as to what constitutes a normal TSH response to TRH is sparse $\mathrm{s}^{1-3}$ and we therefore decided to undertake a retrospective analysis of the results of the TRH stimulation tests on all children successfully submitted to the Health Services Human Growth Hormone Committee from 1977 to 1981 inclusive to try to define responses that were characteristic of normality, hypopituitary, and hypothalamic disorders.

\section{Methods}

During the 5-year period 1977-1981 there were 645 successful applications for GH therapy. In 405 of these a TRH stimulation test had been performed. The tests were carried out mainly in the 20 regional growth centres and consisted of blood samples analysed for TSH before, and 20 and 60 minutes after an intravenous injection of $200 \mu \mathrm{g}$ TRH. The TRH stimulation tests were performed alone or as part of a combined endocrine stimulation test in which insulin, TRH, and luteinising hormone- releasing hormone were injected together. ${ }^{4}$ Many of the samples were analysed in laboratories participating in the supraregional assay service, but some were not. Variation between laboratories in the definition of a normal range for TSH values made it impractical to pool absolute values and the following definitions of normal and abnormal response were made.

Hypopituitary. The TSH values at 0,20 , and 60 minutes fell within the normal basal range for that laboratory and if the 0 minute TSH level was $<2 \mathrm{IU} / \mathrm{ml}$ the rise to the peak value was $<5 \mathrm{IU} / \mathrm{ml}$ or if the 0 minute TSH level was $>2 \mathrm{IU} / \mathrm{ml}$ the rise to the peak value was less than threefold.

Hypothalmic. The 20-minute TSH value was more than five times the upper limit of normal basal range for that laboratory or the 20 minute TSH value was less than the 60 minute value, both results being above the upper limit of the normal basal range for that laboratory.

Normal. All results neither hypothalamic nor hypopituitary.

\section{Patients}

The patients were subdivided into five groups.

Isolated GH deficiency $(n=226)$. These patients were not known to be deficient in any other hormone and had never undergone cranial surgery or radiotherapy. Each was clinically euthyroid and had a normal level of serum thyroxin. 
GH deficiency of known aetiology $(n=64)$. In these patients who were also clinically and biochemically euthyroid, specific cranial damage was thought to be responsible for the isolated GH deficiency. Twentythree of these patients had undergone treatment for pituitary or pituitary axis tumours, 35 had received cranial radiotherapy for other reasons, and 6 suffered from septo-optic dysplasia.

Partial pituitary failure - thyroxin deficient $(n=55)$. Twenty-six of these children required thyroxin and GH therapy alone, 24 required corticosteroid therapy in addition, and 5 required $\mathrm{GH}$, thyroxin, and DDAVP therapy. Thyroxin treatment was considered necessary if the serum thyroxin level was consistently low.

Partial pituitary failure-non-thyroxin deficient $(\mathbf{n}=32)$. Twelve of these children were corticosteroid and GH deficient, 3 were GH and gonadotrophin deficient, 11 were GH deficient and had diabetes insipidus requiring DDAVP therapy, and 6 required corticosteroid, GH, and DDAVP therapy.

Total pituitary failure $(n=28)$. These children required GH, thyroxin, steroid, and DDAVP therapy.

The aetiologies of the patients in the last three groups included pituitary and pituitary axis tumours, cranial radiotherapy for other causes, as well as those who were idiopathic.

\section{Results}

Isolated GH deficiency. Of the 226 patients with idiopathic isolated GH deficiency, $164(72 \%)$ had normal TSH responses to TRH stimulation. The remaining 62 , who were clinically and biochemically euthyroid had hypopituitary $(9 \%)$ or hypothalamic (19\%) responses (Table).

GH deficiency of known aetiology. The non-idiopathic GH only deficient group displayed a markedly different pattern of TSH response. Only $30(47 \%)$ of this group recorded a normal TRH stimulation test, $11(17 \%)$ showed hypopituitary responses, 23 $(36 \%)$ showed hypothalamic TSH responses.

Table TSH response to TRH in children suspected of hypopituitarism

\begin{tabular}{llll}
\hline Diagnosis & Normal & Hypopituitary & Hypothalamic \\
\hline $\begin{array}{l}\text { Isolated GH deficiency } \\
\quad \text { (idiopathic) }\end{array}$ & 164 & 21 & 41 \\
$\begin{array}{c}\text { Isolated GH deficiency } \\
\text { (non-idiopathic) }\end{array}$ & 30 & 11 & 23 \\
$\begin{array}{c}\text { Partial pituitary failure } \\
\text { (thyroxin deficient) }\end{array}$ & 4 & 29 & 22 \\
$\begin{array}{c}\text { Partial pituitary failure } \\
\text { (non-thyroxin deficient) }\end{array}$ & 17 & 6 & 9 \\
\begin{tabular}{c} 
Total pituitary failure \\
\hline
\end{tabular} & 2 & 18 & 8 \\
\hline
\end{tabular}

Partial pituitary failure. Four of the thyroxindependent partial pituitary failure group showed normal TSH responses to the TRH stimulation test. The first was a 17-year old boy who developed hypopituitarism after surgery and radiotherapy for a craniopharyngioma. His TSH levels were 4.9, 17.1, and $13.8 \mathrm{IU} / \mathrm{ml}$ at 0,20 , and 60 minutes respectively (normal for this laboratory $0-7 \cdot 8 \mathrm{IU} / \mathrm{ml}$ ). Nevertheless his pretreatment serum thyroxin level was low. The second child was an 8-year-old boy who had had a stormy neonatal period. He was found to have a low serum thyroxin level but did not grow in response to thyroxin supplements alone. His TSH levels were $3 \cdot 8,21 \cdot 5$, and $18 \cdot 0 \mathrm{IU} / \mathrm{ml}$ at 0,20 , and 60 minutes respectively (normal range $0-10.0$ $\mathrm{IU} / \mathrm{ml}$ for this laboratory). The third child was submitted for GH therapy at age 12 , having become hypopituitary after surgery and radiotherapy for a craniopharyngioma. His TSH responses were 1.5 , 7.6 , and $7.0 \mathrm{IU} / \mathrm{ml}$ at 0,20 , and 60 minutes; however his serum thyroxin level was low. The final child had idiopathic partial pituitary failure requiring both corticosteroid and thyroxin treatment. He was submitted for $\mathrm{GH}$ therapy at age 13 . His TSH results were $1 \cdot 9,12 \cdot 1$, and $9 \cdot 1$ at 0,20 , and 60 minutes (normal laboratory results for the last 2 patients was $0-8.0 \mathrm{IU} / \mathrm{ml})$. The remainder $(92 \%)$ of this group displayed abnormal TRH stimulation tests, $29(53 \%)$ showing hypopituitary responses, the remainder hypothalamic results.

Partial pituitary failure-non-thyroxin deficient. The patients suffering from partial pituitary failure who were not known to be thyroxin deficient showed normal responses to TRH stimulation in $17(53 \%)$ cases. Six $(19 \%)$ of these children showed hypopituitary responses and $9(28 \%)$ showed hypothalamic results.

Total pituitary failure. Only 2 of the patients with total pituitary failure had normal TSH responses to TRH stimulation tests. One of these was a 16-yearold boy who underwent cranial irradiation after presenting with a pinealoma. The serum TSH rose from $<1$ to $7.8 \mathrm{IU} / \mathrm{ml}$ at 20 minutes, dropping to $6.8 \mathrm{IU} / \mathrm{ml}$ at 60 minutes (normal range from that laboratory was $0-8 \mathrm{IU} / \mathrm{ml})$. The other child was an 11-year-old girl, who was diagnosed as having a cystic teratoma (possibly an atypical pinealoma) after having presented 2 years earlier with diabetes insipidus. Her treatment consisted of a combination of surgery and radiotherapy. The serum TSH rose from 4 to $29 \mathrm{IU} / \mathrm{ml}$ at 20 minutes, falling to 23 $\mathrm{IU} / \mathrm{ml}$ at 60 minutes. All other $26(93 \%)$ children in this group had abnormal TRH stimulation tests; $18(64 \%)$ of these showed hypopituitary responses, the rest hypothalamic responses. 


\section{Discussion}

This study shows that abnormal TSH responses to TRH are commonly found in children with GH deficiency who are clinically and biochemically euthyroid. This observation is based on definitions of normal and abnormal response that allow for variations in assay techniques between laboratories. If TSH assay methods were more reproducible it would be possible to define normal, hypopituitary, and hypothalamic responses in absolute terms, but as this is not so (C Wilde, personal communication), and these definitions are therefore useful for the analysis of large numbers.

Since all the children studied were considered, both by the referring physician and the Health Services Human Growth Hormone Committee, to be GH deficient they were, by virtue of probable preexisting pituitary disease, more likely to have abnormal TSH secretion than normal children. Certain subgroups were expected to have abnormal TSH secretion because the patients were known to have pituitary or hypothalamic structural damage or because they were clinically hypothyroid. The hypothyroidism would be expected to be of pituitary or hypothalamic origin with the exception of those in whom cranio-spinal irradiation had directly affected the thyroid gland or those in whom primary hypothyroidism concurrently existed. Normal TSH response to TRH was observed in 2 of 28 cases with total pituitary failure and in 4 of 55 patients known to be hypothyroid. The concordance between the clinical state and the test results provides good empirical support for the definition used for a normal response.

More interesting are the children who were known to have structural damage to the hypothalamic-pituitary axis who appeared to be suffering from isolated GH deficiency. Only 30 out of 64 such patients showed a normal TSH response to TRH. A similar ratio was observed in patients with partial pituitary failure who were euthyroid, 17 of whom out of 32 showed normal TSH responses. In both these groups it is likely that pituitary or hypothalamic hypothyroidism may become manifest if the patient is kept under clinical supervision.

Most surprising was the number of abnormal TSH responses in the subgroup with idiopathic $\mathrm{GH}$ deficiency. Sixty-two out of 226 had abnormal test results suggesting a pituitary or hypothalamic defect, yet all the patients were clinically euthyroid and had normal serum thyroxin levels.

It might be argued that the abnormal test results were artefactual and a result of the definitions used in this study. This is unlikely because the working definitions were modelled to resemble those previously used ${ }^{125}$ but avoiding the use of numerical terms. Their validity is confirmed in the subgroup of children known to have pituitary or hypothalamic damage and hypothyroidism, in whom there is excellent concordance between the clinical state and TRH test result. Other workers have observed that children respond to TRH tests in the same way as adults $^{13}$ and hypothalamic patterns of TSH secretion on TRH testing have been previously observed in isolated GH deficiency. ${ }^{356}$ Some degree of independence of the pituitary-thyroid axis from TRH has been demonstrated in animals and adults $;^{7}$ if the same is true in children, it would explain the coexistence of euthyroidism and a hypothalamic TSH response. Euthyroidism in the presence of a hypopituitary TSH response is more difficult to explain. Since there is no evidence on the reproducibility of TSH response to TRH in children, it is possible that a proportion of such patients would have had normal results on another occasion.

We thank the Health Services Human Growth Hormone Committee for allowing access to their records; Dr C Wilde and Profesor $\mathrm{R}$ Hall for comments; the directors of the growth centres for providing information on their patients.

\section{References}

1 Foley T P, Jr, Owings J, Hayford J T, Blizzard R M. Serum thyrotropin responses to synthetic thyrotropin releasing hormone in normal children and hypopituitary patients. J Clin Invest 1972; 51 : 431-7.

2 Hall R, Ormston B J, Gesser G M, Cryer R J, McKendrick $M$. The thyrotrophin-releasing hormone test in diseases of the pituitary and hypothalamus. Lancet 1972; i: 759-63.

3 Okada Y, Onishi T, Tanaka K, et al. Prolactin and TSH responses to TRH, chlorpromazine, and L-Dopa in children with human growth hormone deficiency. Acta Endocrinol 1978; 88: 217-26.

4 Frasier S D. Pediatric endocrinology, New York: Grune \& Stratton, 1980: 38-46.

5 De Papendieck L G, Iorcansky S, Rivarola M A, Heinrich J J, Bergadá C. Patterns of TSH response to TRH in children with hypopituitarism. $J$ Pediatr 1982; 100: 387-92.

6 Illig R, Krawczyńska H, Torresani T, Prader A. Elevated plasma TSH and hypothyroidism in children with hypothalamic hypopituitarism. J Clin Endocrinol Metab $1975 ; 41: 722-8$

7 Singer P A, Nicoloff J T. Assessment of thyrotropinreleasing hormone and thyrotrophin reserve in man. J Clin Invest 1973; 52: 1099-107.

Correspondence to Professor R D G Milner, Department of Paediatrics, Children's Hospital, Sheffield S10 2TH.

Received 7 October 1982 